\title{
ANALISIS KEMAMPUAN DAN KEMANDIRIAN KEUANGAN DAERAH SEBAGAI DAYA DUKUNG PELAKSANAAAN PROGRAM SUMBER DAYA AIR DAN KETAHANAN PANGAN
}

\author{
Eko Aristanto \\ Email: aristanto90@gmail.com \\ Fakultas Ekonomi dan Bisnis, Universitas Merdeka Malang \\ J1. Terusan Raya Dieng No. 62-64, Malang - Jawa Timur
}

\begin{abstract}
ABSTRAK
Keberhasilan program sumber daya air dan ketahanan pangan yang sedang dilaksanakan sangat bergantung dukungan dan komitmen pemerintah daerah, termasuk di dalamnya keterdukungan dan kemampuan pembiayaan kegiatan tersebut oleh pemerintah daerah. Penelitian ini bertujuan i) menganalisis kemampuan dan kemandirian keuangan daerah dan ii) menganalisis keuangan daerah sebagai daya dukung pelaksanaan program sumber daya air dan ketahanan pangan. Penelitian ini mengunakan metode penelitian deskriptif, metode pengambilan sampel mengunakan purposive sampling dengan kriteria kabupaten yang menerima Program Integrated Participatory Development and Management of Irrigation Program (IPDMIP) sebanyak 74 kabupaten. Metode analisis data mengunakan Rasio Kemandirian Keuangan Daerah (RMKD), Rasio Kemampuan Rutin Daerah (RKRD), Rasio Derajat Otonomi Fiskal (RDOF) dan Indek Kapasitas Fiskal Daerah (IKFD) dengan periode pengamatan tahun 2018 dan 2019. Hasil analisis kemampuan dan kemandirian keuangan daerah dengan mengunakan 4 variabel RMKD, RKRD, RDOF dan IKFD menjelaskan mayoritas kemampuan dan kemandirian keuangan daerah berada di rentang sangat rendah sampai dengan sedang sejumlah 60 atau $80,4 \%$ dari 74 kabupaten penerima IPDMIP. Rekomendasi penelitian mendorong pemerintah daerah mencapai Disbursement Linked Indicators (DLI) yang telah disepakati dalam skema modalitas Result Based Lending, agar anggaran yang digunakan dalam program IPDMIP dapat reimbursement.
\end{abstract}

Kata Kunci : Kemampuan dan Kemandirian Keuangan Daerah, Program IPDMIP

\section{ABSTRACT}

The success of the water resources and food security program that is being carried out is very dependent on the support and commitment of the local government including the support and ability to finance these activities by the local government.This study aims $i)$ to analyze the ability and independence of regional finances and ii) analyze regional finances as a support for implementing water resources and food security programs. This study uses a descriptive research method, the sampling method uses purposive sampling with the criteria of districts that receive 74 districts of the Integrated Participatory Development and Management of Irrigation Program (IPDMIP). The data analysis method uses the Regional Financial Independence Ratio (RMKD), Regional Routine Capacity Ratio (RKRD), Fiscal Autonomy Degree Ratio (RDOF) and Regional Fiscal Capacity Index (IKFD) with observation periods in 2018 and 2019. The results of the analysis of regional financial capability and independence using 4 variables of RMKD, RKRD, RDOF and IKFD explain the majority of regional financial capability and independence are in the range of Very Low to Medium totaling 60 or $80.4 \%$ of 74 districts receiving IPDMIP. Research recommendations encourage local governments to achieve Disbursement Linked Indicators (DLI) agreed in the Result Based Lending modality scheme, so that the budget used in the IPDMIP program can be reimbursed.

Keyword : Regional Financial Ability and Independence, IPDMIP Program 


\section{PENDAHULUAN}

Ketahanan Pangan merupakan agenda strategis yang dilaksanakan pemerintah dalam rangka menjaga ketersediaan dan kecukupan pangan bagi masyarakat di Indonesia. Dengan jumlah penduduk Indonesia pada tahun 2019 sebanyak 268.074.600 jiwa, maka konsumsi beras sebagai bahan pangan pokoknya mencapai 37,97 juta ton atau 7,88\% dari total konsumsi domestik beras dunia (Kementerian Pertanian, 2019). Sementara data Badan Pusat Statistik tahun 2019 memperkirakan luas panen padi dari 10,68 juta hektar luas mampu menghasilkan beras mencapai 31,31 juta ton. Dengan data tersebut menunjukkan bahwa secara nasional terdapat defisit ketersediaan beras sebesar 6,66 juta ton. Merujuk kondisi tersebut, beras merupakan komoditas pangan strategis yang harus dijamin ketersediaannya melalui intervensi pemerintah untuk menjaga kestabilan ekonomi dan pembangunan nasional (Purwanto, 2018).

Dengan memperhatikan hal di atas, dalam mewujudkan ketahanan pangan dibutuhkan upaya nyata melalui reformasi di bidang pertanian. Salah satu reformasi dengan melakukan pembangunan di bidang sumber daya air dengan memperhatikan pelaksanaan pembangunan wilayah (Aristanto, 2007). Pembangunan di bidang sumber daya air ini, dilakukan melalui kegiatan pembanguna irigasi baru dan rehabilitasi daerah irigasi untuk mendorong ketersediaan, kecukupan dan ketahanan air yang dapat meningkatkan produktivitas pada lahan pertanian. Namun beberapa hambatan peningkatan produktivitas petani di Indonesia meliputi : (i) Kelembagaan petani, air dan irigasi lemah; (ii) Sistem irigasi kurang dan buruk pemeliharaanya (Aminah \& Budhi G.S, 2009; Tri Purwantini \& Suhaeti, 2017); (iii) kurang tenaga dan lemahnya penyuluhan pertanian; (iv) infrastruktur kurang dan buruk pemeliharaanya; (v) akses petani penggarap kepada sumber pembiayaan desa terbatas (Supriyati \& Suryani, Erma, 2006); (vi) kepemilikan lahan tidak jelas (Aristanto, 2020b); dan (vii) kesenjangan teknologi. Disamping fakta lain menunjukkan diperkirakan kurang lebih 100 ribu hektar lahan pertanian telah beralih fungsi menjadi non pertanian tiap tahunnya. Disamping alih fungsi lahan, masalah lain yang dihadapai adalah degradasi kondisi prasarana irigasi. Sementara faktor lain yang mendorong mendesaknya peningkatan kapasitas produktivitas dari luas lahan pertanian yang ada, khususnya padi, adalah potensi laju pertumbuhan penduduk Indonesia yang mencapai $1,4 \%$ per tahunnya yang diikuti dengan pertumbuhan kebutuhan pangannya (Aristanto, 2020c). 
Pembangunan di bidang sumber daya air dilakukan dengan pengembangan prasarana irigasi baru yang bertujuan untuk menyediakan prasarana irigasi pada daerah yang belum ada prasarana irigasi sebelumnya dan rehabilitasi prasarana irigasi untuk menjaga dan mengamankan prasarana irigasi agar selalu dapat berfungsi dengan baik guna memperlancar pelaksanaan operasi dan mempertahankan kelestariannya (Aristanto, et al., 2020). Dalam Peraturan Menteri Pekerjaan Umum dan Perumahan Rakyat Republik Indonesia Nomor 14/PRT/M/2015 tentang Kriteria dan Penetapan Status Daerah Irigasi, menjelaskan jumlah daerah irigasi secara nasional (kewenangan pusat, provinsi dan kabupaten) sebanyak 66.391 DI dengan luasan 9.146.027 Ha menyebar pada 34 Provinsi dan Kabupaten 416 Kabupaten (Kementerian Pekerjaan Umum dan Perumahan Rakyat, 2015). Penilaian cepat (rapid assessment) yang dilakukan Direktorat Jenderal Sumber Daya Air menjelaskan daerah irigasi (DI) target baik di Provinsi dan Kabupaten adalah yang memiliki kondisi jaringan irigasi rusaknya rusak sedang hingga berat yang tidak sepenuhnya dapat ditanggulangi dengan alokasi DAK hingga saat ini.

Upaya untuk mengoptimalisasi fungsi irigasi, maka pemerintah melaksanakan Program Integrated Participatory Development and Management of Irrigation Program (IPDMIP). Program ini akan memprioritaskan rehabilitasi jaringan irigasi air permukaan di daerah lumbung pangan yang belum ditangani oleh kegiatan lain (Kementerian Pekerjaan Umum dan Perumahan Rakyat, 2017). Cakupan program IPDMIP adalah mendukung upaya penguatan kapasitas kelembagaan SDA, pengelola irigasi dan kapasitas pemerintah dalam melaksanakan operasi dan pemeliharaan serta pengelolaan sistem irigasi. Program ini diharapkan akan mendorong pembaharuan-pembaharuan dalam pemerintahan sektor irigasi dalam upaya menjamin berkelanjutannya peningkatan infrastruktur dan OP dan perbaikan pengelolaan.

Program Integrated Participatory Development and Management of Irrigation Project (IPDMIP) memiliki cakupan wilayah program di 74 Kabupaten di dalam 16 provinsi di Indonesia, untuk periode tahun 2017 - 2022. Pelaksanaan program Integrated Participatory Development and Management of Irrigation Program (IPDMIP) secara efektif dilaksanakan tahun 2017 setelah penandatangan Perjanjian Pinjaman ADB No. 3529-INO dan 8327-INO (AIF) antara Direktorat Jenderal Pengelolaan Pembiayaan dan Risiko atas nama Pemerintah 


\section{Jurnal Ekonomi Pembangunan Vol. 6, No.1 (2020) 62-78}

Indonesia dengan Asian Development Bank dan International Fund for Agricultural Development (Aristanto, 2020a). Total anggaran program ini diperkirakan sebesar Rp. 22 triliun (USD 1,679 juta) yang bersumber dari pemerintah indonesia (APBN dan APBD) diperkirakan sebesar Rp 14 triliun (USD 1,079 juta) dan sisanya sebesar Rp 8 triliyiun (USD 600 juta) diperoleh dari sumber lainnya. Skema pinjaman yang bersumber dari ADB (cofinancing AIF) menggunakan skema Result Based Lending (RBL). Dimana Result Based Lending (RBL) merupakan suatu modalitas pembiayaan yang dipergunakan untuk membiayai kegiatan dalam bentuk project/program dengan berbasis pada pencapaian hasil kegiatan (result based).

Tabel 1. Rencana Penggunaan Pinjaman ADB \& AIF untuk Program IPDMIP

\begin{tabular}{llccc}
\hline & \multicolumn{1}{c}{ Komponen } & \multicolumn{2}{c}{ Anggaran (x1000) } \\
\cline { 3 - 5 } & \multicolumn{1}{c}{ IDR } & USD & $\%$ \\
\hline Komponen 1. & $\begin{array}{l}\text { Penguatan Kapasitas Kelembagaan } \\
\text { dan Sistem Irigasi Pertaian yang } \\
\text { berkelanjutan }\end{array}$ & 611.197 .885 & 47.015 & $6,73 \%$ \\
\hline Komponen 2. & $\begin{array}{l}\text { Peningkatan Sistem dan Kapasitas } \\
\text { Pengelolaan, Operasional dan } \\
\end{array}$ & 632.391 .423 & 48.645 & $6,96 \%$ \\
\hline Pemeliharaan Irigasi & $\begin{array}{l}\text { Peningkatan Infrastruktur Sistem } \\
\text { Irigasi }\end{array}$ & 6.556 .410 .692 & 504.339 & $72,20 \%$ \\
\hline Total ADB/AIF & $\begin{array}{l}\text { Meningkatkan Pendapatan Irigasi } \\
\text { Pertanian }\end{array}$ & 1.280 .500 .000 & 98.500 & $14 \%$ \\
\hline Komponen 4 & 9.800 .000 .000 & 600.000 & $86 \%$ \\
\hline Total ADB/AIF + IFAD & & 9.080 .500 .000 & 698.500 & $100 \%$ \\
\hline
\end{tabular}

Sumber : Pedoman Pelaksanaan IPDMIP (2019)

Melalui skema modalitas Result Based Lending (RBL), maka pemerintah daerah menyusun seluruh kegiatan Program Integrated Participatory Development and Management of Irrigation Project (IPDMIP) ke dalam Overall Work Plan (OWP) pemerintah kabupaten dan rencana kegiatan pertahun tertuang dalam Annual Work Plan (AWP) tahun 2018-2022. Implementasi di lapangan, terhadap penyusunan Overall Work Plan (OWP) dan Annual Work Plan (AWP) bagi kabupaten IPDMIP berdampak penyediaan anggaran pelaksanaan kegiatan tersebut yang bersumber dari Anggaran Penerimaan dan Belanja Daerah masing-masing kabupaten IPDMIP. Walaupun pada akhirnya dana tersebut akan diganti melalui pencairan 
pinjaman dilakukan setelah hasil kegiatan tercapai berdasarkan indikator yang disusun dalam Disbursement Linked Indicators (DLI) yang telah disepakati dan diverifikasi BPKP (Kementerian Keuangan, 2019).

Dengan memperhatikan skema modalitas Result Based Lending (RBL), pada akhirnya akan mempengaruhi prioritas penganggaran rutin dan pembangunan daerah. Hal tersebut menjadi pertimbangan bagi pemerintah daerah dalam penganggaran, manakala kebijakan penganggaran berorientasi pada desentralisasi fiskal (Didi Ahmadi, 2015). Dengan pengelolaan fiskal yang dilakukan pemerintah daerah berorientasi desentralisasi fiskal, yang lebih lanjut dijelaskan pada Undang-Undang No. 23 Tahun 2014 tentang Pemerintah Daerah memberikan kewenangan dan otonomi secara luas yang luas, nyata dan bertanggung jawab kepada pemerintah daerah dalam mengelola sumber daya yang dimilikinya untuk meningkatkan kesejahteraan masyarakat (Aisza Faradiba Alfi, \& Nuraini, 2018). Desentralisasi fiskal ini mengacu pada teori fiscal federalism yang mengedepankan prinsip maksimalisasi kesejahteraan (Schneider, 2003).

Kebutuhan dan keberhasilan pelaksanaan Program Integrated Participatory Development and Management of Irrigation Project (IPDMIP) bagi pemerintah daerah, tentunya akan sangat bergantung komitmen dan APBD. Komitmen pemerintah ditunjukkan pada sisi penganggaran program selama 2018 s.d 2022 pada APBD kabupaten pelaksana IPDMIP. Hal tersebut tentunya menuntut kemampuan dan kemandirian keuangan daerah, dimana keuangan merupakan faktor penting dalam mengukur tingkat kemampuan daerah dalam melaksanakan otonominya (Sumardjoko, 2019). Otonomi desentralisasi fiskal (local fiscal autonomy) adalah kemampuan pemerintah daerah dalam meningkatkan Pendapatan Asli Daerah (PAD) yang merupakan salah satu aspek penting dalam otonomi daerah (Saputra, 2017). Kemampuan daerah yang dimaksud adalah sampai seberapa jauh daerah dapat menggali sumber-sumber keuangannya sendiri guna membiayai kebutuhan daerah tanpa harus selalu menggantungkan diri pada bantuan dan subsidi dari pemerintah pusat (Rante et al., 2017; Aristanto \& Ratnaningsih, 2019).

Menurut pendapat Halim (2008) menjelaskan ciri utama daerah yang mampu melaksanakan desentralisasi fiskal yaitu: (1). Kemampuan keuangan daerah, artinya daerah harus memiliki kewenangan dan kemampuan untuk menggali sumber sumber keuangan, 
mengelola dan menggunakan keuangan sendiri yang cukup memadai untuk membiayai penyelenggaraan pemerintahannya. (2). Ketergantungan kepada bantuan pusat harus seminimal mungkin, agar pendapatan asli daerah (PAD) harus menjadi bagian sumber keuangan terbesar, yang didukung oleh kebijakan perimbangan keuangan pusat dan daerah, sehingga peranan pemerintah daerah menjadi lebih besar. Namun kenyataan menunjukkan terdapat beberapa faktor penyebab utama rendahnya kemandirian daerah pada beberapa pemeritah daerah meliputi : 1) rendahnya potensi PAD daerah bersangkutan; atau 2) beban belanja APBD yang relatif besar di era desentralisasi fiskal ( Hidayat, 2016) (Risyanto, 2015). Dengan mendasarkan pada latar belakang tersebut, penelitian ini bertujuan : i) menganalisis kemampuan dan kemandirian keuangan daerah dan ii) menganalisis keuangan daerah sebagai daya dukung pelaksaaan program sumber daya air dan ketahanan pangan. Adapun penelitian ini melakukan analisis kemampuan dan kemandirian keuangan daerah pada kabupaten pelaksana Program Integrated Participatory Development and Management of Irrigation Project (IPDMIP) tahun 2018 s.d 2019.

\section{METODE PENELITIAN}

Penelitian ini mengunakan pendekatan deskriptif kuantitatif bertujuan melakukan pengukuran kemampuan dan kemandirian keuangan daerah pada kabupaten penerima program Integrated Participatory Development and Management of Irrigation Program (IPDMIP). Data yang digunakan adalah data time series yang membandingkan rasio-rasio keuangan daerah periode tahun 2018 dan 2019. Adapun metode pengambilan sampel mengunakan purposive sampling dengan dasar pertimbangan sampel penelitian adalah kabupaten yang mendapat intervensi program IPDMIP. Adapun sampel penelitian adalah kabupaten penerima program IPDMIP sebagai berikut :

Tabel 2. Kabupaten penerima program IPDMIP sebagai sampel penelitian.

\begin{tabular}{clll}
\hline No & \multicolumn{1}{c}{ Provinsi } & \multicolumn{3}{c}{ Kabupaten Program } \\
\hline 1. & Aceh & Aceh Timur, Aceh Besar, Aceh Utara, Bireuen \\
\hline 2. & Sumatera Utara & $\begin{array}{l}\text { Asahan, Simalungun, Tapanuli Tengah, Humbang } \\
\text { Hasundutan }\end{array}$ \\
\hline 3. & Sumatera Barat & $\begin{array}{l}\text { Pasaman, Limapuluh Kota, Sijunjung, Pasaman Barat, } \\
\text { Pesisir Selatan }\end{array}$ \\
\hline
\end{tabular}




\begin{tabular}{cll}
\hline No & \multicolumn{1}{c}{ Provinsi } & \multicolumn{3}{c}{ Kabupaten Program } \\
\hline 4. & Sumatera Selatan & $\begin{array}{l}\text { Musi } \\
\text { Banyuasin, Banyuasin, Muara Enim dan Lahat }\end{array}$ \\
\hline 5. & Lampung & $\begin{array}{l}\text { Pesawaran, Tulangbawang, Tanggamus, Lampung Tengah, } \\
\text { Mesuji, Lampung Selatan }\end{array}$ \\
\hline 6. & Banten & Pandeglang, Serang \\
\hline 7. & Jawa Barat & $\begin{array}{l}\text { Indramayu, Garut, Kuningan, Ciamis, Sukabumi, } \\
\text { Majalengka }\end{array}$ \\
\hline 8. & Jawa Tengah & $\begin{array}{l}\text { Kebumen, Banjarnegara, Pati, Purworejo, Pekalongan, } \\
\text { Banyumas, Cilacap }\end{array}$ \\
\hline 9. & Jawa Timur & $\begin{array}{l}\text { Jombang, Bojonegoro, Ngawi, Lamongan, Kediri, Madiun, } \\
\text { Lumajang, Jember, Tuban }\end{array}$ \\
\hline 10. & Kalimantan Barat & Sambas, Kayong Utara, Ketapang, Kubu Raya \\
\hline 11. & Kalimantan Selatan & Tanah Bumbu, Hulu Sungai Tengah, Tapin, Barito Kuala \\
\hline 12. & Sulawesi Utara & Minahasa Selatan, Bolaang Mongondow \\
\hline 13. & Sulawesi Tengah & Toli-Toli, Poso, Bangai \\
\hline 14. & Sulawesi Selatan & Wajo, Pinrang, Sidenreng Rappang, Soppeng, Bone \\
\hline 15. & Nusa Tenggara Barat & Lombok Timur, Bima, Lombok Tengah, Dompu \\
\hline 16. & Nusa Tenggara Timur & Manggarai Timur, Manggarai Barat \\
\hline & &
\end{tabular}

Metode pengumpulan data dan informasi adalah desk dokumen keuangan daerah yang bersumber dari masing-masing APBD penerima program IPDMIP tahun 2018 dan 2019.

Adapun variabel, sub variabel, pengukuran dan skala kemampuan dan kemandirian keuangan daerah pada tabel 2 sebagai berikut :

Tabel 3. Variabel, Sub Variabel, Pengukuran dan Skala Kemampuan dan Kemandirian Keuangan Daerah

\begin{tabular}{|c|c|c|c|}
\hline Variabel & Sub. Variabel & Pengukuran & Skala \\
\hline \multirow{4}{*}{$\begin{array}{l}\text { Keuangan } \\
\text { Daerah }\end{array}$} & $\begin{array}{l}\text { Kemandirian } \\
\text { Keuangan Daerah }\end{array}$ & $\begin{array}{l}\text { Rasio Kemandirian Keuangan } \\
\text { Daerah (RMKD) }\end{array}$ & Rasio \\
\hline & $\begin{array}{l}\text { Kemampuan Rutin } \\
\text { Daerah }\end{array}$ & $\begin{array}{l}\text { Rasio Ketergantungan Keuangan } \\
\text { Daerah (RKRD) }\end{array}$ & Rasio \\
\hline & $\begin{array}{l}\text { Derajat Otonomi } \\
\text { Fiskal }\end{array}$ & $\begin{array}{l}\text { Rasio Derajat Otonomi Fiskal } \\
\text { (RDOF) }\end{array}$ & Rasio \\
\hline & $\begin{array}{l}\text { Kapasitas Fiskal } \\
\text { Daerah }\end{array}$ & $\begin{array}{l}\text { Indek Kapasitas Fiskal Daerah } \\
\text { (IKFD) }\end{array}$ & Rasio \\
\hline
\end{tabular}

Sumber : Data Sekunder, 2019 (diolah) 


\section{Jurnal Ekonomi Pembangunan Vol. 6, No.1 (2020) 62-78}

Adapun analisis dan pengujian data dalam penelitian ini mengunakan 4 (empat) teknik analisis data keuangan daerah (Halim, Abdul, 2008; Mardiasmo, 2007), yaitu : 1) Rasio Kemandirian Keuangan Daerah (RMKD); 2) Rasio Kemampuan Rutin Daerah (RKRD); 3) Rasio Derajat Otonomi Fiskal (RDDF) dan 4). Indek Kapasitas Fiskal Daerah (IKFD). Adapun masing-masing rumus rasio kemampuan dan kemandirian keuangan daerah, sebagai berikut :

Rasio Kemandirian Keuangan Daerah (RMKD)

\begin{tabular}{lrr}
$\begin{array}{l}\text { Rasio Kemampuan Rutin } \\
\text { Daerah (RKRD) }\end{array}$ & \multicolumn{1}{c}{$\begin{array}{c}\text { Pendapatan Asli Daerah } \\
\text { Rasio Derajat Otonomi Belanja Rutin } \\
\text { Fiskal (RDOF) }\end{array}$} \\
$\begin{array}{ll}\text { Indek Kapasitas Fiskal } \\
\text { Daerah (IKFD) }\end{array}$ & $\begin{array}{l}\text { Pendapatan Asli Daerah } \\
\text { Total Pendapatan Daerah }\end{array}$ \\
& $=\begin{array}{l}\text { tentang Peta Kapasitas Fiskal Daerah 2018 } \\
\text { dan } 2019\end{array}$
\end{tabular}

$$
=\frac{\text { Pendapatan Asli Daerah }}{\text { Transfer Pemerintah Pusat dan Provinsi }}
$$

\section{HASIL DAN PEMBAHASAN}

Program sumber daya air dan ketahanan pangan yang menjadi fokus penelitian ini adalah Integrated Participatory Development and Management of Irrigation Program (IPDMIP) yang sedang berjalan mulai tahun 2018 s.d 2022. Penelitian ini mengambil sampel kabupaten yang sedang melaksanakan Program Integrated Participatory Development and Management of Irrigation Program (IPDMIP) dengan jumlah sampel 74 sebanyak kabupaten. Variabel penelitian adalah kemampuan dan kemandirian keuangan daerah dengan indikator yaitu Rasio Kemandirian Keuangan Daerah (RMKD), Rasio Kemampuan Rutin Daerah (RKRD), Rasio Derajat Otonomi Fiskal (RDOF) dan Indek Kapasitas Fiskal Daerah (IKFD) . Adapun deskripsi data kemampuan dan kemandirian keuangan daerah mengunakan deskripsi data yang meliputi maksimum, minimum, rata-rata (mean) dan nilai standar deviasi masing-masing variabel kemampuan dan kemandirian keuangan daerah sebagai berikut : 
Tabel 3. Deskripsi Data Variabel Kemampuan dan Kemandirian Keuangan Daerah

\begin{tabular}{cccccc}
\hline $\begin{array}{c}\text { Desciptive } \\
\text { Statistic }\end{array}$ & N & Minimum & Maximum & Mean & $\begin{array}{c}\text { Std. } \\
\text { Deviation }\end{array}$ \\
\hline RMKD & 148 & 0,029 & 0,416 & 0,137 & 0,068 \\
\hline RKRD & 148 & 0,076 & 0,923 & 0,385 & 0,157 \\
\hline RDOF & 148 & 0,027 & 0,248 & 0,099 & 0,041 \\
\hline IKFD & 148 & 0,095 & 5,307 & 1,086 & 0,669 \\
\hline
\end{tabular}

Sumber: Hasil Pengolahan, 2020

Deskripsi data variabel kemampuan dan kemandirian keuangan daerah di atas, yang meliputi Rasio Kemandirian Keuangan Daerah (RMKD), Rasio Kemampuan Rutin Daerah (RKRD), Rasio Derajat Otonomi Fiskal (RDOF) dan Indek Kapasitas Fiskal Daerah (IKFD) memiliki nilai mean lebih besar dari standart deviasi menjelaskan bahwa data memiliki kecenderungan angka yang hampir sama satu sama lainnya.

Tabel 4. Hasil Perhitungan Rasio Kemandirian Keuangan Daerah (RMKD)

\begin{tabular}{|c|c|c|c|c|}
\hline \multirow{2}{*}{ Variabel } & \multicolumn{2}{|c|}{ Kategori } & \multicolumn{2}{|c|}{ Kabupaten } \\
\hline & Nilai & Makna & Jumlah & $\%$ \\
\hline \multirow{5}{*}{$\begin{array}{l}\text { Rasio Kemandirian } \\
\text { Keuangan Daerah } \\
\text { (RMKD) }\end{array}$} & $0-25 \%$ & Sangat Rendah & 138 & 93,2 \\
\hline & $26 \%-50 \%$ & Rendah & 10 & 6,8 \\
\hline & $51 \%-75 \%$ & Sedang & - & \\
\hline & $76 \%-100 \%$ & Tinggi & - & \\
\hline & & Jumlah & 148 & 100 \\
\hline
\end{tabular}

Sumber : Analisis Data, 2020

Hasil analisis Rasio Kemandirian Keuangan Daerah (RMKD) terhadap 74 kabupaten IPDMIP menunjukan kabupaten dengan nilai terendah pada tahun 2018 sebesar 2,91\% dan nilai terendah pada tahun 2019 sebesar 3,22 \% adalah Kabupaten Kayong Utara. Untuk rasio kemandirian keuangan daerah kabupaten dengan nilai tertinggi pada tahun 2018 sebesar 37,47 $\%$ adalah Kabupaten Simalungun, sedangkan kabupaten dengan nilai tertinggi pada tahun 2019 sebesar 41,64 \% adalah Kabupaten Serang. Pola penyebaran Rasio Kemandirian Keuangan Daerah (RMKD) menunjukkan kabupaten yang terbanyak pada kategori sangat sebanyak 138 (93,2\%) kabupaten dan kabupaten yang terendah pada kategori rendah sebanyak $10(6,8 \%)$. Kondisi tersebut menjelaskan bahwa kemampuan keuangan daerah dengan 
mengunakan indikator Rasio Kemandirian Keuangan Daerah (RMKD) mayoritas berada di rentang Sangat Rendah s.d Rendah sejumlah 148 atau 100\% dari 74 kabupaten penerima IPDMIP. Kondisi tersebut, menjelaskan bahwa secara mayoritas kabupaten penerima program IPDMIP menunjukkan tingginya ketergantungan pemerintah kabupaten program IPDMIP terhadap transfer pemerintah pusat dan provinsi di banding dengan kemampuan pemerintah daerah dalam menghasilkan pendapatan asli daerah dari berbagai sektor ekonomi. Rendahnya rasio kemandirian keuangan daerah tersebut, menunjukan upaya pemerintah daerah dalam mengali sumber-sumber penerimaan daerah belum optimal. Kondisi tersebut membutuhkan kemauan dan kreativitas pemerintah daerah untuk mencari sumber-sumber pembiayaan dalam upaya mendorong peningkatan pendapatan asli daerah.

Tabel 5. Hasil Perhitungan Rasio Kemampuan Rutin Daerah (RKRD)

\begin{tabular}{|c|c|c|c|c|}
\hline \multirow{2}{*}{ Variabel } & \multicolumn{2}{|c|}{ Kategori } & \multicolumn{2}{|c|}{ Kabupaten } \\
\hline & Nilai & Makna & Jumlah & $\%$ \\
\hline \multirow{6}{*}{$\begin{array}{l}\text { Rasio Kemampuan } \\
\text { Rutin Daerah (RKRD) }\end{array}$} & $0-10 \%$ & Sangat Rendah & 2 & 1,4 \\
\hline & $10,01 \%-20,00 \%$ & Rendah & 13 & 8,8 \\
\hline & $20,01 \%-40,00 \%$ & Sedang & 70 & 47,3 \\
\hline & $40,01 \%-50,00 \%$ & Tinggi & 32 & 21,6 \\
\hline & $>50,01$ & Sangat Tinggi & 31 & 20,9 \\
\hline & & Jumlah & 148 & 100 \\
\hline
\end{tabular}

Sumber : Analisis Data, 2020

Hasil analisis Rasio Kemampuan Rutin Daerah (RKRD) menunjukan kabupaten dengan nilai terendah pada tahun 2018 sebesar 7,6 \% dan tahun 2019 sebesar 8,4 \% adalah Kabupaten Kayong Utara. Untuk Rasio Kemampuan Rutin Daerah (RKRD) menunjukan kabupaten dengan nilai tertinggi pada tahun 2018 sebesar 92,3 \% adalah Kabupaten Simalungun, sedangkan kabupaten dengan nilai tertinggi pada tahun 2019 sebesar 76,8 \% adalah Kabupaten Serang. Pola penyebaran Rasio Kemampuan Rutin Daerah (RKRD) menunjukkan kabupaten yang terbanyak pada kategori sedang sebanyak 70 (47,2\%) kabupaten dan kabupaten yang terendah pada kategori sangat rendah sebanyak 2 (1,4\%). Kondisi tersebut menjelaskan bahwa kemampuan keuangan daerah dengan mengunakan indikator Rasio Kemampuan Rutin Daerah (RKRD) mayoritas berada di rentang Sangat Rendah s.d Sedang sejumlah 85 atau 57,4\% dari 
74 kabupaten penerima IPDMIP. Merujuk pada hasil perhitungan Rasio Kemampuan Rutin Daerah (RKRD) menunjukan 57,5\% dari sampel kabupaten penerima program IPDMIP masih memiliki ketergantungan yang tinggi terhadap transfer dari pemerintah pusat dan provinsi dalam pelaksanaan pembangunan di daerahnya. Belanja rutin merupakan elemen penting dalam proses pelaksanaan kegiatan pembangunan di daerah, ketidakmampuan pemerintah daerah dalam memenuhi belanja rutin akan sangat menganggu kinerja pemerintah dalam dalam menjalankan roda pemerintahan dan pembangunan. Kecenderungan yang terjadi pada 74 kabupaten penerima Program IPDMIP menjelaskan masih rendahya kemampuan pemerintah daerah dalam mengali pendapatan asli daerah dalam membiayai berbagai belanja rutin.

Tabel 6. Hasil Perhitungan Rasio Derajat Otonomi Fiskal (RDOF)

\begin{tabular}{|c|c|c|c|c|}
\hline \multirow{2}{*}{ Variabel } & \multicolumn{2}{|c|}{ Kategori } & \multicolumn{2}{|c|}{ Kabupaten } \\
\hline & Nilai & Makna & Jumlah & $\%$ \\
\hline \multirow{6}{*}{$\begin{array}{l}\text { Rasio Derajat Otonomi } \\
\text { Fiskal (RDOF) }\end{array}$} & $0-10 \%$ & Sangat Kurang & 87 & 58,8 \\
\hline & $10,01 \%-20,00 \%$ & Kurang & 58 & 39,2 \\
\hline & $20,01 \%-40,00 \%$ & Sedang & 3 & 2,0 \\
\hline & $40,01 \%-50,00 \%$ & Baik & - & \\
\hline & $>50,01$ & Sangat Baik & - & \\
\hline & & Jumlah & 148 & 100 \\
\hline
\end{tabular}

Sumber : Analisis Data, 2020

Hasil analisis Rasio Derajat Otonomi Fiskal (RDOF) menunjukan kabupaten dengan nilai tertinggi pada tahun 2018 sebesar 2,7\% dan tahun 2019 sebesar 2,9 \% adalah Kabupaten Kayong Utara. Untuk rasio Rasio Derajat Otonomi Fiskal (RDOF) menunjukkan kabupaten dengan nilai tertinggi pada tahun 2018 sebesar 23,5 \% adalah Kabupaten Simalungun, sedangkan kabupaten dengan nilai tertinggi pada tahun 2019 sebesar 24,8 \% adalah Kabupaten Serang. Pola penyebaran Rasio Derajat Otonomi Fiskal (RDOF) menunjukkan kabupaten yang terbanyak pada kategori sangat rendah sebanyak 87 (58,8\%) kabupaten dan kabupaten yang terendah pada kategori sangat rendah sebanyak 3 (2,0 \%). Kondisi tersebut menjelaskan bahwa kemampuan keuangan daerah dengan mengunakan indikator Rasio Derajat Otonomi Fiskal (RDOF) mayoritas berada di rentang Sangat Rendah s.d Sedang sejumlah 148 atau $100 \%$ dari 74 kabupaten penerima IPDMIP. Merujuk pada hasil perhitungan Rasio Derajat 
Otonomi Fiskal (RDOF) menjelaskan bahwa kemampuan daerah untuk menghasilkan pendapatan asli daerah untuk mendukung pendapatan daerah yang masih terbatas. Keterbatasan pendapatan asli daerah yang belum mampu dioptimalkan tersebut mengakibatkan pemerintah daerah masih bergantung pada transfer dari pemerintah pusat dan provinsi dalam membiayai berbagai pos belanja rutin dan pembangunan yang harus dilaksanakanan oleh pemerintah daerah.

Tabel 7. Hasil Perhitungan Indek Kapasitas Fiskal Daerah (IKFD)

\begin{tabular}{|c|c|c|c|c|}
\hline \multirow{2}{*}{ Variabel } & \multicolumn{2}{|c|}{ Kategori } & \multicolumn{2}{|c|}{ Kabupaten } \\
\hline & Nilai & Makna & Jumlah & $\%$ \\
\hline \multirow{6}{*}{$\begin{array}{l}\text { Indek Kapasitas Fiskal } \\
\text { Daerah (IKFD) }\end{array}$} & IFKD $<0,53$ & Sangat Rendah & 19 & 12,8 \\
\hline & $0,53 \leq \mathrm{IFKD}<0,72$ & Rendah & 30 & 20,3 \\
\hline & $0,72 \leq \mathrm{IFKD}<1,14$ & Sedang & 46 & 31,1 \\
\hline & $1,14 \leq \mathrm{IFKD}<2,05$ & Tinggi & 41 & 27,7 \\
\hline & IFKD $\geq 2,05$ & Sangat Tinggi & 12 & 8,1 \\
\hline & & Jumlah & 148 & 100 \\
\hline
\end{tabular}

Sumber : Analisis Data, 2020

Untuk Indek Kapasitas Fiskal Daerah (IKFD) menunjukan kabupaten dengan nilai terendah pada tahun 2018 sebesar 0,095 adalah Kabupaten Bima, sedangkan kabupaten dengan nilai terendah pada tahun 2019 sebesar 0,218 adalah Kabupaten Aceh Besar. Sedangkan Indek Kapasitas Fiskal Daerah (IKFD) dengan nilai tertinggi pada tahun 2018 sebesar 2,703 adalah Kabupaten Jember, sedangkan kabupaten dengan nilai tertinggi pada tahun 2019 sebesar 5,307 adalah Kabupaten Bojonegoro. Pola penyebaran Indek Kapasitas Fiskal Daerah (IKFD) menunjukkan kabupaten yang terbanyak pada kategori sedang sebanyak $46(31,5 \%)$ kabupaten dan kabupaten yang terendah pada kategori sangat tinggi sebanyak 12 $(8,3 \%)$. Kondisi tersebut menjelaskan bahwa kemampuan keuangan daerah dengan mengunakan indikator Indek Kapasitas Fiskal Daerah (IKFD) mayoritas berada di rentang Sangat Rendah s.d Sedang sejumlah 95 atau 64,2\% dari 74 kabupaten penerima IPDMIP. Merujuk pada hasil perhitungan Indek Kapasitas Fiskal Daerah (IKFD) mejelaskan bahwa sebagai besar kabupaten penerima Program IPDMIP merupakan daerah-daerah yang memiliki kapasitas sangat rendah s.d sedang. Dengan kapasitas fiskal yang sangat terbatas, mengakibatkan kemampuan pemerintah daerah dalam menjalankan agenda pembangunan 
yang bersifat pembangunan infrastruktur sangat terbatas. Dalam kontek Program IPDMIP menunjukan bahwa keberadaan program tersebut dapat mendorong pemerintah daerah dapat melakukan pembangunan infrastruktur yang berkaitan dengan sumber daya air dalam bentuk pembangunan rehabilitasi bendungan dan rehabilitasi jarigan irigasi dengan skema pinjaman luar negeri. Hal tersebut membantu pemeritah daerah yang memiliki keterbatasan keuangan untuk melakukan perbaikan berbagai bendungan dan rehabilitasi daerah irigasi yang sangat penting, menginggat kabupaten penerima Program IPDMIP merupakan daerah-daerah penyedia/lumbung pangan nasional.
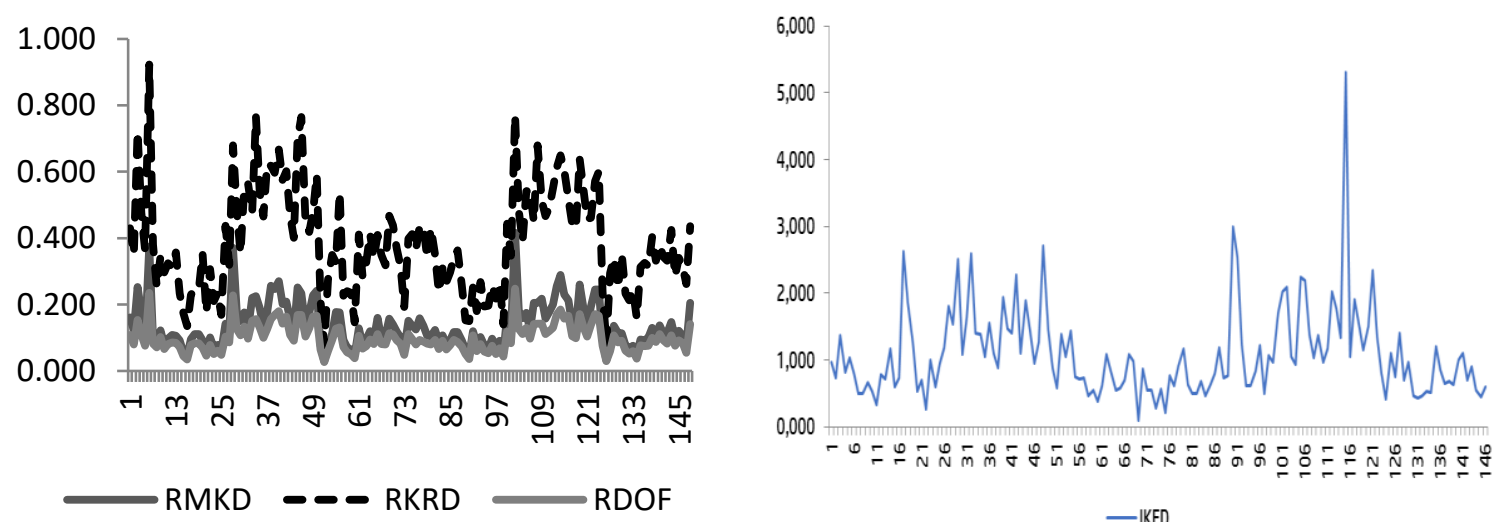

Gambar 1. Sebaran variabel RKMD, RKRD, RDOF dan IKFD dari 74 Kabupaten IPDMIP Periode 2018-2019

Merujuk pada gambar 1 dijelaskan pola sebaran data Rasio Kemandirian Keuangan Daerah (RMKD), Ketergantungan Keuangan Daerah (RKKD), Rasio Derajat Otonomi Fiskal (RDOF) dan Indek Kapasitas Fiskal Daerah (IKFD) menunjukkan nilai rata-rata lebih tinggi dengan nilai standar devisasi menunjukan kecenderungan pola data yang relatif sama (homogen) terhadap data 74 kabupaten IPDMIP selama periode 2018 sd 2019. Berdasarkan hasil analisis terhadap seluruh variabel kemampuan dan kemandirian keuangan daerah yang Rasio Kemandirian Keuangan Daerah (RMKD), Ketergantungan Keuangan Daerah (RKKD), Rasio Derajat Otonomi Fiskal (RDOF) dan Indek Kapasitas Fiskal Daerah (IKFD) dan menjelaskan bahwa : i) kabupaten dengan kategori sangat rendah sejumlah 62 atau 41,6 \%; ii) kabupaten dengan kategori rendah sejumlah 28 atau 18,8\%; iii) kabupaten dengan kategori cukup sejumlah 30 atau 20,1 \%; iv) kabupaten dengan kategori tinggi sejumlah 18 atau 12,3 $\%$; dan i) kabupaten dengan kategori sangat tinggi sejumlah 11 atau 7,3\%. Analisis 
kemampuan dan kemampuan daerah keuangan daerah dengan mengunakan seluruh variabel mayoritas berada di rentang Sangat Rendah s.d Sedang sejumlah 60 atau 80,4\% dari 74 kabupaten penerima IPDMIP. Kecenderungan yang terjadi pada beberapa indikator di atas, menjelaskan bahwa kabupaten penerima Program IPDMIP merupakan kabupaten yang memiliki kemampuan dan kemandirian keuangan daerah yang rendah. Terdapat beberapa faktor yang secara umum mengakibatkan hal tersebut, antara lain belum optimalnya pemerintah daerah dalam mengali berbagai sumber-sumber pendapatan asli daerah, terdapat kabupaten pemekaran baru pada penerima Program Program IPDMIP yang kemampuan pengelolaan keuangan daerahnya masih rendah, ketergantungan yang masih tinggi pada penerimaan yang bersumber dari transfer pemeritah pusat dan provinsi. Melalui Program IPDMIP mendorong pemerintah daerah untuk dapat melakukan rehabilitasi bendungan dan jaringan irigasi, dengan mengunakan skema pinjaman luar negeri. Hal tersebut memberikan keuntungan bagi pemerintah daerah dalam bentuk manfaat pembiayaan pembangunan yang berkaitan dengan sumber daya air yang mendukung kegiatan pertanian. Namun yang perlu dan penting dipahami pemerintah daerah dengan skema modalitas Result Based Lending pada Program IPDMIP, maka pemerintah harus membiayai terlebih dahulu pelaksanaa kegiatan rehabilitasi bendungan dan jaringan irigasi sebagai bentuk kesungguhan dan komitmen pemerintah daerah dalam program ini, setelah verifikasi dan ketercapaian Disbursement Linked Indicators (DLI) yang telah disepakati sangat penting, maka anggaran APBD yang telah digunakan dalam Program IPDMIP dapat di reimbursement, untuk dikembalikan kembali pada APBD kabupaten IPDMIP sehingga dapat melakukan pembiayaan pembangunan lainnya.

\section{KESIMPULAN}

Berdasarkan hasil analisis kemampuan dan kemandirian keuangan daerah menunjukkan bahwa : 1) Rasio Kemandirian Keuangan Daerah (RMKD) menunjukkan kabupaten yang terbanyak pada kategori sangat sebanyak $138(93,2 \%)$ kabupaten dan kabupaten yang terendah pada kategori rendah sebanyak 10 (6,8\%); ii) Rasio Kemampuan Rutin Daerah (RKRD) menunjukkan kabupaten yang terbanyak pada kategori sedang sebanyak $70(47,2 \%)$ kabupaten dan kabupaten yang terendah pada kategori sangat rendah sebanyak 2 (1,4\%); iii) Rasio Derajat Otonomi Fiskal (RDOF) menunjukkan kabupaten yang terbanyak pada kategori 
sangat rendah sebanyak $87(58,8 \%)$ kabupaten dan kabupaten yang terendah pada kategori sangat rendah sebanyak 3 (2,0 \%); dan iv) Indek Kapasitas Fiskal Daerah (IKFD) menunjukkan kabupaten yang terbanyak pada kategori sedang sebanyak 46 (31,5\%) kabupaten dan kabupaten yang terendah pada kategori sangat tinggi sebanyak $12(8,3 \%)$.

Analisis terhadap seluruh variabel kemampuan dan kemandirian keuangan daerah yang Rasio Kemandirian Keuangan Daerah (RMKD), Ketergantungan Keuangan Daerah (RKKD), Rasio Derajat Otonomi Fiskal (RDOF) dan Indek Kapasitas Fiskal Daerah (IKFD) dan menjelaskan bahwa : i) kabupaten dengan kategori sangat rendah sejumlah 62 atau 41,6 \%; ii) kabupaten dengan kategori rendah sejumlah 28 atau 18,8\%; iii) kabupaten dengan kategori cukup sejumlah 30 atau 20,1\%; iv) kabupaten dengan kategori tinggi sejumlah 18 atau 12,3 $\%$; dan i) kabupaten dengan kategori sangat tinggi sejumlah 11 atau 7,3\%. Dengan demikian menunjukkan kemampuan dan kemandirian keuangan daerah, secara mayoritas berada di rentang Sangat Rendah s.d Sedang sejumlah 60 atau 80,4\% dari 74 kabupaten penerima IPDMIP. Hasil tersebut memberikan temuan bahwa kabupaten penerima Program IPDMIP merupakan kabupaten yang memiliki kemampuan dan kemandirian keuangan daerah yang rendah. Faktor -faktor yang menyebabkan rendahnya kemampuan dan kemandirian keuangan daerah, antara lain belum optimalnya pemerintah daerah dalam mengali berbagai sumbersumber pendapatan asli daerah, terdapat kabupaten pemekaran baru pada penerima Program Program IPDMIP yang kemampuan pengelolaan keuangan daerahnya masih rendah dan ketergantungan yang masih tinggi pada penerimaan yang bersumber dari transfer pemeritah pusat dan provinsi. Rekomendasi penelitian mendorong pemerintah daerah mencapai Disbursement Linked Indicators (DLI) yang telah disepakati dalam skema modalitas Result Based Lending, agar anggaran yang digunakan dalam program IPDMIP dapat reimbursement.

\section{DAFTAR PUSTAKA}

Aisza Faradiba Alfi, Syarifah, \& Nuraini, Ida. (2018). Analisis Pengelolaan Keuangan Daerah Terhadap Produk Domestik Regional Bruto (PDRB) di Kabupaten/Kota Provinsi Kalimantan Selatan. Jurnal Ilmu Ekonomi, Vol. 2, Jilid 3, 500-513.

Aminah, Mimin, \& Budhi G.S. (2009). Pattern of Farmers' Participation: Lessons from Pump Irrigation Project. Analisis Kebijakan Pertanian, Vol. 7 No. 4, 251-368.

Aristanto, Eko. (2007). Evaluasi Dampak Sosial Ekonomi Program Pengembangan Kawasan di Propinsi Jawa Timur. Universitas Merdeka Malang, LPPM. 
Aristanto, Eko. (2020a). Capaian Konsultan Pendukung Dalam Pelaksanaan Program Integrated Participatory Development \& Management of Irrigation Program (IPDMIP) di Kabupaten Pandeglang dan Kabupaten Serang. Buletin Pembangunan Daerah, Vol. 1, No. 1, 1-5.

Aristanto, Eko. (2020b). Pemetaan Aspek Sosial, Ekonomi dan Kelembagaan Sebagai Daya Dukung Pelaksanaan Rehabilitasi Daerah Irigasi (DI) Ciliman Provinsi Banten. LPPM Universitas Merdeka Malang.

Aristanto, Eko. (2020c). Profil dan Kinerja Kelembagaan Perkumpulan Petani Pemakai Air (P3A) Daerah Irigasi (DI) Ciliman di Kabupaten Lebak dan Kabupaten Pandeglang. LPPM Universitas Merdeka Malang.

Aristanto, Eko, Hidayatullah, Syarif, Dinata, Chandra, \& Adi Prabowo, Kuncoro. (2020). Perancangan Dashboard Perencanaan Pembangunan Irigasi Daerah Mendukung Ketahanan Pangan. Jurnal Pengabdian Kepada Masyarakat MEMBANGUN NEGERI, Vol. 4, No. 1, 84-97.

Aristanto, Eko, \& Sri Ratnaningsih, Christina. (2019). Analisis Kemampuan dan Kemandirian Keuangan Daerah Calon Penerima Pinjaman dan Hibah Luar Negeri Program Air Bersih dan Sanitasi pada Kegiatan Green Book 2018 dan Indikasi Kegiatan Blue Book 2019. LPPM Universitas Merdeka Malang.

Didi Ahmadi. (2015). Desentralisasi dan Pembangunan Daerah di Indonesia: Menciptakan Pemerintah Daerah yang Efektif, Responsif dan Akuntabel. Jurnal Pembangunan Daerah, III, 23-40.

Halim, Abdul. (2008). Akuntansi Sektor Publik Akuntansi Keuangan Daerah. Salemba Empat.

Hidayat, Muhammad. (2016). Analisis Kemampuan Keuangan kabupaten/kota di Provinsi Sumatera Barat dalam Era Otonomi Daerah. Jurnal Sungkai, Vol. 4, No. 2.

Kementerian Keuangan. (2019). Penarikan Pinjaman Luar Negeri: Mekanisme Rekening Khusus Result Based Lending (RBL). Direktorat Pengelolaan Kas Negara, Direktorat Jenderal Perbendaharaan.

Kementerian Pekerjaan Umum dan Perumahan Rakyat. (2015). Peraturan Menteri Pekerjaan Umum dan Perumahan Rakyat Republik Indonesia Nomor 14/PRT/M/2015 tentang Kriteria dan Penetapan Status Daerah Irigasi. Peraturan Menteri Pekerjaan Umum dan Perumahan Rakyat Republik Indonesia Nomor 14/PRT/M/2015 tentang Kriteria dan Penetapan Status Daerah Irigasi.

Kementerian Pekerjaan Umum dan Perumahan Rakyat. (2017). Pedoman Pelaksanaan Program Integrated Participatory Development and Management of Irrigation Program (IPDMIP). Kementerian Pekerjaan Umum dan Perumahan Rakyat.

Kementerian Pertanian. (2019). Konsumsi dan Neraca Penyediaan-Penggunaan Beras. In Buletin Konsumsi Pangan: Vol. Vol. 10, No. 1. Pusat Data dan Sistem Informasi Pertanian, Sekretariat Jenderal, Kementerian Pertanian.

Mardiasmo. (2007). Otonomi dan Manajemen Keuangan Daerah (Edisi 2). Andi Publisher. 
Paramita Purwanto, Niken. (2018). Ketersediaan Pasokan dan Distribusi Beras Nasional. Kajian Singkat Terhadap Isu Aktual Dan Strategis Bidang Ekonomi Dan Kebijakan Publik, Vol. X, No. 18, 19-24.

Purwantini, Tri Bastuti, \& Nur Suhaeti, Rita. (2017). Irigasi Kecil: Kinerja, Masalah dan Solusinya. Forum Penelitian Agro Ekonomi, 35 No. 2, 91-105.

Rante, Aris, Saleh Mire, Muhammad, \& Paminto, Ardi. (2017). Analisis Kemandirian Keuangan Daerah. INOVASI, Volume 13 (2), 92-103.

Risyanto, Hilmi. (2015). Analisis Kemampuan Keuangan Daerah dan Kemandirian Keuangan Daerah serta Pengaruhnya Terhadap Pertumbuhan Ekonomi Kabupaten Garut Tahun Anggaran 2004-2013. Competition, Vol. VI, No. 1, 21-33.

Saputra, Rinaldi. (2017). Analisis Derajat Desentralisasi atau Kemandirian Keuangan Daerah Dalam Pelaksanaan Otonomi Daerah di Aceh Tamiang. Jurnal Samudra Ekonomika, Vol. 1, No. 1, 12-21.

Schneider, Aaron. (2003). Decentralization: Conceptualization and Measurement. Studies in Comparative International Development, 38(3), 32-56.

Sumardjoko, Imam. (2019). Penguatan Kinerja Keuangan Daerah Wilayah Kepulauan dan Implikasinya terhadap Perubahan Fundamental Ekonomi Regional. Jurnal Desentralisasi Fiskal, Ekonomi Dan Keuangan Daerah, Volume V, Edisi 5, 1-23.

Supriyati, \& Suryani, Erma. (2006). Peranan, Peluang dan Kendala Pengembangan Agroindustri di Indonesia. Forum Penelitian Agra Ekonomi, 24 No. 2, 92-106. 